\title{
The outcome of patients treated with salvage surgery after chemo-radiotherapy for locally advanced non-small cell lung carcinoma
}

\author{
Marco Nardini ${ }^{1}$, Alessandro Pardolesi ${ }^{2}$ \\ ${ }^{1}$ Thoracic Surgery and Lung Transplant Unit, Fondazione IRCCS Ca Granda Ospedale, Maggiore Policlinico, University of Milan, Milan, Italy; \\ ${ }^{2}$ Division of Thoracic Surgery, Fondazione IRCCS Istituto Nazionale dei Tumori, Milan, Italy \\ Contributions: (I) Conception and design: Both authors; (II) Administrative support: Both authors; (III) Provision of study materials or patients: \\ Both authors; (IV) Collection and assembly of data: Both authors; (V) Data analysis and interpretation: Both authors; (VI) Manuscript writing: Both \\ authors; (VII) Final approval of manuscript: Both authors. \\ Correspondence to: Alessandro Pardolesi, MD. Division of Thoracic Surgery, Fondazione Istituto Nazionale dei Tumori, Via Venezian 1, CAP Milan, \\ Italy. Email: alessandro.pardolesi@istitutotumori.mi.it.
}

\begin{abstract}
Local relapse or persistent disease after definitive chemo radiotherapy for locally advanced nonsmall cell lung cancer (NSCLC) occurs in $24 \%$ to $35 \%$ of patients. Patients treated with chemo-radiotherapy or surgery alone have a poor prognosis. Therefore, some authors described salvage surgery after definitive concurrent chemo radiotherapy in the attempt to prolong disease free and overall survival. Although initially considered inoperable, selected patients are evaluated for salvage surgery. Even if it is a challenging operation, when indicated, salvage surgery is technically feasible in centres with dedicated expertise and is leading to acceptable morbidity, mortality, and long-term outcomes, even when extended resections are necessary. Careful patient selection and multidisciplinary meeting are crucial to deciding on salvage lung resection. The literature is mainly in the form of retrospective studies and case series, there is lack of strong evidence and randomized clinical trial, therefore salvage surgery after definitive medical treatment should be offered within a study protocol in order to produce stronger evidence behind its adoption. In this brief review, we evaluate the prognosis of patients treated with salvage surgery after definitive chemo-radiotherapy for locally advanced NSCLC. We also underline the main critical points related with its adoption and indications.
\end{abstract}

Keywords: Lung cancer; salvage surgery; advanced stage

Received: 24 April 2020; Accepted: 11 June 2020; Published: 25 February 2021.

doi: $10.21037 /$ ccts-20-88

View this article at: http://dx.doi.org/10.21037/ccts-20-88

\section{Introduction}

The term locally advanced non-small cell lung cancer (NSCLC) refers to a large and heterogeneous disease, for which the best therapeutic options [induction treatment, surgery and/or definitive chemo-radiotherapy (CT-RT)] are still under investigation. Patients who underwent surgery alone or definitive CT-RT have reduced long-term survival rates that range from $5 \%$ to $25 \%(1-3)$. Concurrent CTRT with high dose radiotherapy has been widely adopted as a chance of cure when patients are considered inoperable.
Nevertheless, $24 \%$ to $35 \%$ of these patients do not respond to the treatment or develop local recurrences and surgery should be considered a "salvage therapy" to improve patients' survival if other medical treatments are not available (4).

Salvage surgery has an established role in many fields of thoracic oncology, particularly for the treatment of metastatic diseases to the lung (5-8). However, the potential benefits of salvage surgery as a therapeutic option for locally advanced NSCLC after definitive CT-RT is still under debate. 
To date, only a few studies report the results of surgery after curative intent CT-RT with high-dose (>59 Gy) radiotherapy. In this brief review, we will address this issue and evaluate the prognosis of patients treated with salvage surgery after radical treatment (CT-RT) for locally advanced NSCLC.

\section{Methods}

Articles were identified by a computer-assisted search of the literature. Search strategy was applied to PubMed from 1998 to 2019. Key words and terms used included "salvage surgery, non small cell lung cancer, locally advanced non small cell lung cancer, definitive chemoradiotherapy" The search was further refined using the following limitations: "English language" and "human".

\section{Definition of salvage surgery}

Salvage surgery is defined as the surgical resection of recurrent or persistent NSCLC, at least three months after CT-RT with curative intent in patients initially excluded from surgical resection. All clinical cases require discussion at multidisciplinary lung cancer meeting, and surgery could be considered if there are reasonable chances to obtain an R0 resection and there are no other therapeutic options or in the presence of urgent symptoms such as haemoptysis. Selection of patients is the most critical aspects to obtain positive benefits of salvage surgery, and a careful re-staging should be performed before indicating surgery as salvage therapeutic option. Chest computed tomography (CT) scan and fluorodeoxyglucose (FDG)-positron emission tomography (PET) scan are essential for completing the re-staging when relapse or recurrent disease is suspected; however, re-staging only by imaging can be inaccurate due to high false-negative and false-positive rates. New histological confirmation of the neoplasm should consider as mandatory when discussing indication to surgery.

Endobronchial ultrasound bronchoscopy (EBUS) is usually performed when radiological findings are suggestive for lymph nodes involvement. EBUS provides acceptable sensitivity and specificity of $67 \%$ and $99 \%$ respectively, with a low rate of complications. However, EBUS presents some limitations, such as the availability of equipment and expertise, and the occurrence of false-negative or falsepositive results when aspirated mediastinal nodes are close to the mass (9). Nevertheless, EBUS should be considered as the preferred diagnostic procedure over mediastinoscopy when performing re-staging for locally advanced NSCLC. While mediastinoscopy is still a pillar in the algorithm of the European Society of Thoracic Surgery for the staging of NSCLC, its safety is dramatically reduced when the procedure is offered after few months from high-dose radiation on the mediastinum (10). In the future, innovative molecular medicine technologies could potentially facilitate early identification of local recurrence or residual malignancy after curative treatment. Assessment of circulating tumour cells plays an important role in defining potential benefits of salvage surgery since dissemination of the disease at the cellular level, is substantially associated with reduced progression-free survival and lower overall survival (11).

Furthermore, novel imaging techniques, such as PET/ magnetic resonance imaging (MRI) could further improve diagnosis of recurrent tumour and differentiate it from fibrotic/inflammatory changes related to CT-RT, leading to a more accurate indication to surgical resection (12-15).

Selection criteria for salvage surgery can be summarized as follow:

* Patients fit for surgery: careful pre-operative cardiorespiratory evaluation;

* No other therapeutic options;

* Accurate Re-staging: new histological confirmation of viable tumour and absence of extrathoracic diseases (16).

\section{Discussion}

A retrospective analysis of 40 patients who underwent surgical resection after definitive CT-RT for NSCLC was reported by Sonett et al. (17). The median time between radiotherapy and surgery was two months. The authors reported a surprising no postoperative mortality. This was probably due to a careful patients' selection criteria, different radiation technique, systematic coverage of bronchial stump after pneumonectomy and enhancements in the postoperative care.

Bauman and co-authors, in 2008 (18), retrospectively described the outcome of 24 patients recruited for surgery from 1997 to 2005. These patients were divided into three groups: patients in group A presented local relapse documented by CT scan, group B had only FGD-PET abnormalities, and group $\mathrm{C}$ were conversions to trimodally treatment. They concluded that surgery was feasible and that the survival was higher among patients who underwent resection for abnormal FDG-PET than for local relapse 
detected by CT scan. The results of this study underline the importance of pathological tissue confirmation before indicating salvage surgery. The diagnosis of residual disease or recurrence on CT and PET-CT scans after CTRT can be misleading, and we, therefore, believe that an attempt should be made to obtain pathological evidence of recurrent disease before indicating a high-risk surgical procedure.

In 2009, Cerfolio explored the topic of surgery after high dose radiation. In a retrospective study, they analysed the outcome of 216 patients, accrued over 10 years, and who underwent a previous median dose of radiation of 60 Gy (range, 60-72 Gy). They concluded that surgery was safe, with a reasonable complication rate. They reported two bronchopleural fistulas after right pneumonectomy and no fistulas after lobectomy. The bronchial stump was buttressed either intercostal flap or omentum. Older age, poor preoperative pulmonary function test and smoking history were statistically significantly associated with postoperative morbidity and operative mortality.

The authors also observed that re-do mediastinoscopy after radiation therapy of the mediastinum could be ineffective and unsafe (19).

The randomized multi-centric trial published by Albain et al. (20) was focused on comparing the overall survival of 202 patients diagnosed with T1-3pN2M0 NSCLC. Patients were randomly assigned in a 1:1 ratio to concurrent induction chemotherapy with cisplatin and etoposide plus radiotherapy (45 Gy). If no progression occurred, patients were divided into two groups: group 1 underwent resection, group 2 continued radiotherapy uninterrupted up to $61 \mathrm{~Gy}$. Two cycles of adjuvant cisplatin and etoposide were administered in both groups. They concluded that overall survival was improved in the patients who underwent lobectomy, but not for patients who underwent pneumonectomy. However, neither of the two treatment options is significantly superior. The disease-free survival was worse in the non-surgical group while mortality related to the intervention was higher in the operative group

Dickhoff and colleagues (21) in 2016, conducted a study of over 15 patients with clinical evidence of recurrence or persistent disease. Patients were scheduled for anatomical pulmonary resection, and 8 of them underwent pneumonectomy. The morbidity rate was as high as $40 \%$, while the 90 -day mortality rate was $6.7 \%$ (1 patient). The estimated median overall and event-free survivals were 46 and 43.6 months, respectively. The benefits and favourable long-term outcome of salvage surgery were also demonstrated by Uramoto et al. (22). The authors reported the outcomes of salvage operations performed in 16 patients; They found a 5 -year overall survival rate in salvage surgery patients of $40.4 \%$ and they observed that salvage surgery could be performed safely with low morbidity rate and promising long-term survival.

In 2017, Casiraghi and co-authors (23) published the outcome of 35 patients, accrued over ten years, who underwent surgery for local recurrence after definitive CT-RT (58 Gy). In this study were included patients who underwent major resection (vascular sleeve, tracheal sleeve pneumonectomy, intrapericardial pneumonectomy, superior cava vein resection and reconstruction) and exploratory thoracotomies. The authors found that the survival rate was causally related to the R0 resection, with a median survival of 27 months in this group. They also reported a 30 days mortality of $5.7 \%$ (2 patients). On our opinion, these data underline the importance of preoperative workup to confirm radical resection (R0).

A systematic review of the literature published, again by Dickhoff in 2018, attempted to define better the management of patient scheduled for salvage surgery. The authors analyzed a total of 158 clinical cases from 8 retrospectives studies. Patients included in these analyses were also those converted to trimodally treatment, and patients who underwent surgery for complications due to radiotherapy. The authors concluded that the limited data in support of salvage surgery after radical CT-RT are very heterogeneous with a low level of evidence. The apparent survival benefit of the patients undergoing surgery may be related to a selection bias. As the patients were fit, with limited disease, and a high chance of $\mathrm{R} 0$ resection. The overall 30 - and 90 -day mortality rate was high: $3 \%$ and $6.5 \%$ respectively (24) (Table 1 ).

The advent of immunotherapy for targeted ligands represent an ongoing "revolution" in the treatment of advanced pulmonary malignancies. The role of surgery in patients who received immunotherapy is still under investigation, and up to date, there are no consistent data available. Immunotherapy seems to cause an intense fibrotic reaction which makes subsequent surgical intervention more challenging and potentially may negatively affect postoperative morbidity.

\section{Limitations}

There are several a few limitations related to study. This is a narrative review and not a systematic review of the 
Table 1 Oncological outcome and surgical strategies of published studies of patients undergoing salvage surgery for advanced NSCLC

\begin{tabular}{|c|c|c|c|c|c|}
\hline Authors & $\begin{array}{l}\text { Number of } \\
\text { patients }\end{array}$ & Methods & Overall survival & Surgical procedures & Bronchial stump coverage \\
\hline $\begin{array}{l}\text { Sonett } \\
\text { et al. (17) }\end{array}$ & 40 & Retrospective analysis & $56.4 \%$ at 5 years & Lobectomies and pneumonectomies & Systematic, intercostal flaps \\
\hline $\begin{array}{l}\text { Bauman } \\
\text { et al. (18) }\end{array}$ & 24 & Retrospective analysis & Median OS 30 months & $\begin{array}{l}\text { Wedge, Lobectomies, bilobectomies } \\
\text { and pneumonectomies }\end{array}$ & Omental and/or muscle flaps \\
\hline $\begin{array}{l}\text { Dickhoff } \\
\text { et al. }(21)\end{array}$ & 15 & Retrospective analysis & Median OS 46 months & Lobectomies and pneumonectomies & - \\
\hline $\begin{array}{l}\text { Casiraghi } \\
\text { et al. (23) }\end{array}$ & 24 & Retrospective analysis & $37 \%$ at 3 years & $\begin{array}{l}\text { Lobectomies, pneumonectomies, } \\
\text { vascular resection }\end{array}$ & Not described \\
\hline
\end{tabular}

NSCLC, non-small cell lung cancer; OS, overall survival.

literature. All data were collected retrospectively. Moreover, due to the small sample sizes, caution should be used in the interpretation of the results.

\section{Conclusions}

To date, there are weak and heterogeneous data on salvage surgery after curative-intent treatment of locally advanced NSCLC. Therefore, it is not possible to draw definitive conclusions. Salvage surgery is technically challenging, the anatomy is profoundly modified by the fibrotic reaction to chemo and radiotherapy, and extensive resections are often required to provide an $\mathrm{R} 0$ surgical margin.

A careful patient's selection and the surgical expertise allow for successful salvage lung resections with acceptable morbidity.

Substantial evidence needs to be produced, preferably be mean of randomized controlled trials and the procedure should be offered within the setting of a research protocol.

\section{Acknowledgments}

Funding: None.

\section{Footnote}

Provenance and Peer Review: This article was commissioned by the Guest Editors (Davide Tosi and Alessandro Palleschi) for the series "The Treatment of Locally Advanced Lung Cancer" published in Current Challenges in Thoracic Surgery.
The article has undergone external peer review.

Conflicts of Interest: All authors have completed the ICMJE uniform disclosure form (available at https://ccts.amegroups. com/article/view/10.21037/ccts-20-88/coif). The series "The Treatment of Locally Advanced Lung Cancer" was commissioned by the editorial office without any funding or sponsorship. The authors have no other conflicts of interest to declare.

Ethical Statement: The authors are accountable for all aspects of this work in ensuring that questions related to the accuracy or integrity of any part of this work are appropriately investigated and resolved.

Open Access Statement: This is an Open Access article distributed in accordance with the Creative Commons Attribution-NonCommercial-NoDerivs 4.0 International License (CC BY-NC-ND 4.0), which permits the noncommercial replication and distribution of the article with the strict proviso that no changes or edits are made and the original work is properly cited (including links to both the formal publication through the relevant DOI and the license). See: https://creativecommons.org/licenses/by-nc-nd/4.0/.

\section{References}

1. Furuse K, Fukuoka M, Kawahara M, et al. Phase III study of concurrent versus sequential thoracic radiotherapy in combination with mitomycin, vindesine, and cisplatin in 
unresectable stage III non-small-cell lung cancer. J Clin Oncol 1999;17:2692-9.

2. Curran WJ, Scott CB, Langer CJ, et al. Long-term benefit is observed in a phase III comparison of sequential versus concurrent chemoradiation for patients with unresected stage III non-small cell lung cancer: RTOG 9410. Proc Amer Soc Clin Oncol 2003;22:621.

3. Farray D, Mirkovic N, Albain KS. Multimodality therapy for stage III non-small-cell lung cancer. J Clin Oncol 2005;23:3257-69.

4. Paramanathan A, Solomon B, Collins M. Patients treated with platinum-doublet chemotherapy for advanced nonsmall-cell lung cancer have inferior outcomes if previously treated with platinum-based chemoradiation. Clin Lung Cancer 2013;14:508-12.

5. Pastorino U, Gasparini M, Valente M, et al. Primary childhood osteosarcoma: the role of salvage surgery. Ann Oncol 1992;3 Suppl 2:S43-6.

6. Pastorino U, Yang XN, Francese M, et al. Long-term survival after salvage surgery for invasive thymoma with intracardiac extension. Tumori 2008;94:772-6.

7. Pastorino U, Gasparini M, Tavecchio L, et al. The contribution of salvage surgery to the management of childhood osteosarcoma. J Clin Oncol 1991;9:1357-62.

8. Kempf-Bielack B, Bielack SS, Jürgens $\mathrm{H}$, et al. Osteosarcoma relapse after combined modality therapy: an analysis of unselected patients in the Cooperative Osteosarcoma Study Group (COSS). J Clin Oncol 2005;23:559-68.

9. Osinka K, Zielińska-Krawczyk M, Korczyński P, et al. Impact of Endobronchial Ultrasound Guided Transbronchial Needle Aspiration on Diagnostic Yield of Bronchoscopy in Patients with Mediastinal Lymph Node Enlargement. Adv Exp Med Biol 2016;911:33-43.

10. De Leyn P, Dooms C, Kuzdzal J. Revised ESTS guidelines for preoperative mediastinal lymph node staging for non-small-cell lung cancer. Eur J Cardiothorac Surg 2014;45:787-98.

11. Nakanishi K, Mizuno T, Sakakura N, et al. Salvage surgery for small cell lung cancer after chemoradiotherapy. Jpn J Clin Oncol 2019;49:389-92.

12. Chaudhuri AA, Chabon JJ, Lovejoy AF. Early detection of molecular residual disease in localized lung cancer by circulating tumor DNA profiling. Cancer Discov 2017;7:1394-403

13. D'Amico A, Pennazza G, Santonico M, et al. An investigation on electronic nose diagnosis of lung cancer. Lung Cancer 2010;68:170 $\square$.
14. Chinniah C, Aguarin L, Cheng P. Prospective trial of circulating tumor cells as a biomarker for early detection of recurrence in patients with locally advanced non-small cell lung cancer treated with chemoradiation therapy. Presented at the Multidisciplinary Thoracic Cancers Symposium, 16-18 March 2017, San Francisco, USA.

15. Fernández-Pérez G, Sánchez-Escribano R, García-Vicente AM, et al. SEOM-SERAM-SEMNIM guidelines on the use of functional and molecular imaging techniques in advanced non-small-cell lung cancer. Clin Transl Oncol 2018;20:837 $\square 52$.

16. Bertolaccini L, Spaggiari L. Salvage pneumonectomy after definitive chemo-radiotherapy. Shanghai Chest 2020;4:14.

17. Sonett JR, Suntharalingam M, Edelman MJ, et al. Pulmonary Resection After Curative Intent Radiotherapy (>59 Gy) and Concurrent Chemotherapy in Non-Small-Cell Lung Cancer. Ann Thorac Surg 2004;78:1200-5.

18. Bauman JE, Mulligan MS, Martins RG. Salvage lung resection after definitive radiation (>59 Gy) for non-small cell lung cancer: surgical and oncologic outcomes. Ann Thorac Surg 2008;86:1632-8.

19. Cerfolio RJ, Bryant AS, Jones VL. Pneumonectomy for lung cancer after preoperative concurrent chemotherapy and high-dose radiation. Pulmonary resection after concurrent chemotherapy and high dose (60Gy) radiation for non-small cell lung cancer is safe and may provide increased survival. Eur J Cardiothorac Surg 2009;35:718-23.

20. Albain KS, Swann RS, Rusch VW, et al. Radiotherapy plus chemotherapy with or without surgical resection for stage III non-small cell lung cancer: a phase III randomised controlled trial. Lancet 2009;374:379-86.

21. Dickhoff C, Dahele M, Paul MA, et al. Salvage surgery for locoregional recurrence or persistent tumor after high dose chemoradiotherapy for locally advanced non-small cell lung cancer. Lung Cancer 2016;94:108-13.

22. Uramoto H, Nakajima Y, Kinoshita H, et al. Equivalent Outcome of Patients with Locally Advanced NSCLC Treated with Salvage Surgery Compared to Induction Chemotherapy Followed by Surgical Resection. Anticancer Res 2016;36:4243-7.

23. Casiraghi M, Maisonneuve P, Piperno G, et al. Salvage Surgery After Definitive Chemoradiotherapy for Nonsmall Cell Lung Cancer. Semin Thorac Cardiovasc Surg 2017;29:233ロ41. 
24. Dickhoff C, Otten RHJ, Heymans MW, et al. Salvage surgery for recurrent or persistent tumour after radical (chemo)radiotherapy for locally advanced non-small cell lung cancer: a systematic review. Ther Adv Med Oncol 2018;10:1758835918804150.

doi: $10.21037 /$ ccts-20-88

Cite this article as: Nardini M, Pardolesi A. The outcome of patients treated with salvage surgery after chemo-radiotherapy for locally advanced non-small cell lung carcinoma. Curr Chall Thorac Surg 2021;3:7. 